Research Article

\title{
Treatment of Severe Ptosis by Conjoint Fascial Sheath Suspension
}

\author{
Pengfei Sang, Mingsong Fang, Xuan Li, Chang Liu, and Qingchun Xi $\mathbb{D}$
}

Department of Plastic Surgery, Hefei Second People's Hospital, China

Correspondence should be addressed to Qingchun Xi; xqc981101@163.com

Received 23 July 2021; Revised 30 September 2021; Accepted 20 October 2021; Published 19 November 2021

Academic Editor: Jianxin Shi

Copyright (c) 2021 Pengfei Sang et al. This is an open access article distributed under the Creative Commons Attribution License, which permits unrestricted use, distribution, and reproduction in any medium, provided the original work is properly cited.

Objective. To explore the role of conjoint fascial sheath (CFS) suspension in the treatment of severe ptosis. Methods. A total of 110 patients with severe ptosis who were admitted to our hospital from May 2018 to December 2020 were included. Fifty-seven patients treated with frontalis suspension were assigned into group A, and the remaining 53 patients treated with CFS suspension were assigned into group B. The curative effect, ocular surface alterations, complications, and satisfaction in the two groups were compared. Results. Patients in group B suffered from severe upper eyelid retraction and lid lag than those in group $\mathrm{A}$, as well as more limited range of motion $(\mathrm{ROM})(P<0.05)$. The curative effect and patient satisfaction in group $\mathrm{B}$ were higher than those in group A $(P<0.05)$. Postsurgical complications in group B were fewer than those in group A $(P<0.05)$. Conclusion. CFS suspension is effective in the treatment of severe ptosis.

\section{Introduction}

Blepharoptosis is common in ocular plastic surgery and may be induced by multiple mechanisms, for example, congenital ptosis caused by low function of fibroadipose tissue in levator palpebrae superioris (LPS) muscle, myogenic ptosis caused by dysgenesis-induced weakness of LPS muscle, and neurogenic ptosis caused by complete or partial loss of cranial nerve III $[1,2]$. Blepharoptosis refers to the drooping of either or both sides of the upper eyelid, resulting in narrow palpebral fissure and covering the eyes [3], which may also be associated with other eye diseases or systemic diseases $[4,5]$. Aponeurosis repair and levator myectomy are preferred options for its treatment. Frontalis suspension, a common surgical treatment for patients with severe ptosis and poor levator function [6], establishes a connection between frontalis and tarsus, thus correcting the position of eyelid through the elevatory force of the frontalis [7]. However, it cannot fully meet the normal physiological requirements and is commonly associated with postoperative keratitis, and vulnerable patients are prone to corneal complications [8]. Conjoint fascia sheath (CFS) has been histologically confirmed to be a kind of fascial tissue membrane with elasticity and toughness. It is widely used in ptosis correction by connecting the special muscle sheath of the levator in the CFS with levator muscle to suspend eyelid [9]. This study is aimed at exploring the role of CSF suspension in the treatment of severe ptosis.

\section{Data and Methods}

2.1. General Data. A total of 110 patients with severe ptosis who were admitted to our hospital from May 2018 to December 2020 were included. Fifty-seven patients treated with frontalis suspension were assigned into group $\mathrm{A}$, and the remaining 53 patients treated with CFS suspension were assigned into group $\mathrm{B}$.

\subsection{Exclusion and Inclusion Criteria}

2.2.1. Inclusion Criteria. The criteria include patients with upper eyelid covering the cornea of about $2 / 3$ or more and upper eyelid levator muscle strength $>4.0 \mathrm{~mm}$ [10]. This study was approved by the Ethics Committee of our hospital, and all participants signed informed consent forms.

2.2.2. Exclusion Criteria. The criteria include patients with communication disorders, relevant treatment history, oculomotor nerve dysfunction, ocular myasthenia gravis, strabismus, or jaw-winking syndrome. 
TABle 1: General data $(x \pm \mathrm{SD})[n(\%)]$.

\begin{tabular}{|c|c|c|c|c|}
\hline Classification & $\begin{array}{c}\text { Group A } \\
(n=57)\end{array}$ & $\begin{array}{c}\text { Group B } \\
(n=53)\end{array}$ & $t / \chi^{2}$ & $P$ \\
\hline Sex & & & 1.182 & 0.277 \\
\hline Male & $33(57.89)$ & $36(67.92)$ & & \\
\hline Female & $24(42.11)$ & $17(32.08)$ & & \\
\hline Age (years) & $24.58 \pm 7.29$ & $25.15 \pm 7.40$ & 0.406 & 0.685 \\
\hline Height (cm) & $171.57 \pm 5.68$ & $172.32 \pm 6.31$ & 0.656 & 0.513 \\
\hline Weight (kg) & $54.21 \pm 8.38$ & $55.43 \pm 7.65$ & 0.795 & 0.428 \\
\hline Residence & & & 0.616 & 0.251 \\
\hline Rural & $21(36.84)$ & $22(41.51)$ & & \\
\hline Urban & $36(63.16)$ & $31(58.49)$ & & \\
\hline Nationality & & & 0.275 & 1.191 \\
\hline Han nationality & $40(70.18)$ & $42(79.25)$ & & \\
\hline $\begin{array}{c}\text { Ethnic } \\
\text { minorities }\end{array}$ & $17(29.82)$ & $11(20.75)$ & & \\
\hline Economic level & & & 1.413 & 0.493 \\
\hline Poor & $12(21.05)$ & $8(15.09)$ & & \\
\hline Well-off & $26(45.61)$ & $30(56.60)$ & & \\
\hline Wealthy & $19(33.33)$ & $15(28.30)$ & & \\
\hline Staying up late & & & 1.695 & 0.193 \\
\hline Yes & $35(61.40)$ & $26(49.06)$ & & \\
\hline No & $22(38.60)$ & $27(50.94)$ & & \\
\hline Exercise & & & 0.344 & 0.557 \\
\hline Yes & $28(49.12)$ & $29(54.72)$ & & \\
\hline No & $29(50.88)$ & $24(45.28)$ & & \\
\hline Obesity & & & 0.257 & 0.611 \\
\hline Yes & $13(22.81)$ & $10(18.87)$ & & \\
\hline No & 44 (77.19) & $43(81.13)$ & & \\
\hline Smoking & & & 1.674 & 0.195 \\
\hline Yes & $21(36.84)$ & $26(49.06)$ & & \\
\hline No & $36(63.16)$ & $27(50.94)$ & & \\
\hline Drinking & & & 0.018 & 0.891 \\
\hline Yes & $24(42.11)$ & $23(43.40)$ & & \\
\hline No & 33 (57.89) & $30(56.60)$ & & \\
\hline Type & & & 1.169 & 0.279 \\
\hline Congenital & $42(73.68)$ & $34(64.15)$ & & \\
\hline Acquired & $15(26.32)$ & $19(35.85)$ & & \\
\hline
\end{tabular}

2.3. Methods. Patients in group A underwent frontalis suspension: two to three drops of tetracaine gel were used for topical anesthesia, and $20 \mathrm{~g} / \mathrm{L}$ lidocaine was used for subcutaneous and subconjunctival infiltration anesthesia. Skin and subcutaneous tissue were incised to expose orbicularis oculi, and the frontalis muscle was separated through an incision above the eyebrow arch. A tunnel was made on each pedicel of muscle flaps through a $5 \mathrm{~mm}$ incision, and mattress sutures of two muscle flaps were pull out from the eyebrow incision through the tunnel. The frontalis muscle and subcutaneous tissue were bluntly dissected upwards to 15$20 \mathrm{~mm}$ above the eyebrow arch, with a width of $25-35 \mathrm{~mm}$.

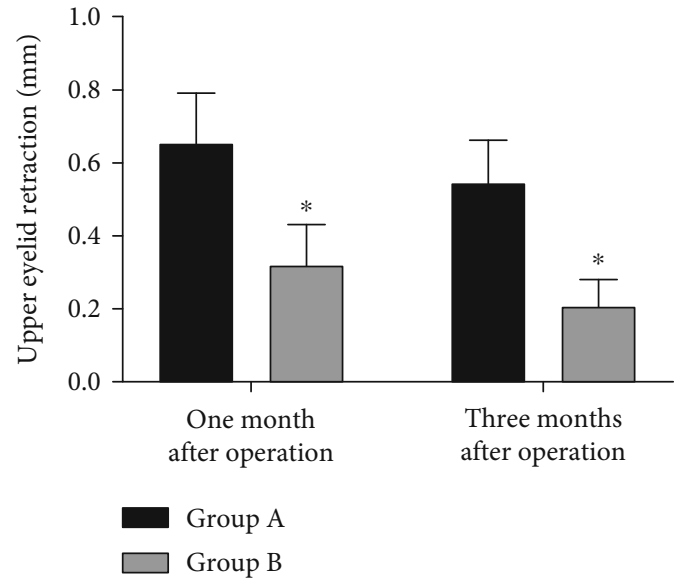

FIGURE 1: Comparison of upper eyelid retraction after surgery. Upper eyelid retraction length in group $B$ is shorter than that in group $A$ at 1 month and 3 months after surgery $(P<0.05) .{ }^{*} P<0.05 v$ s. group $A$.
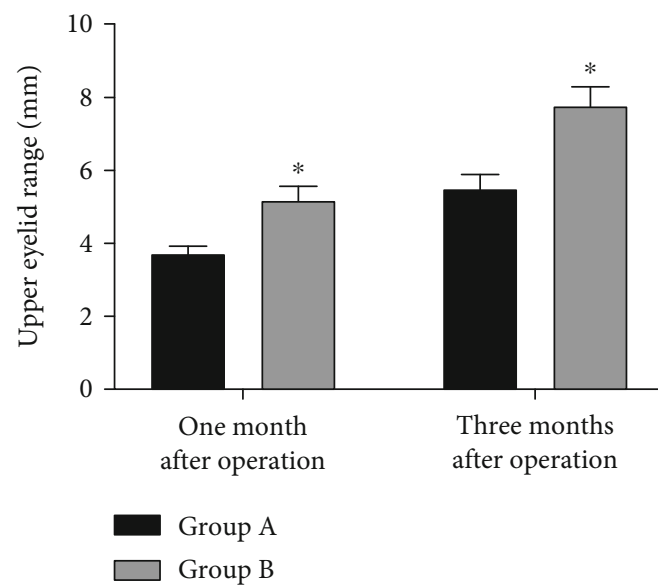

FIgURE 2: Comparison of ROM of upper eyelid after surgery. ROM of upper eyelid in group B is larger than that in group A at 1 month and 3 months after surgery $(P<0.05) .{ }^{*} P<0.05 v$ s. group $\mathrm{A}$.

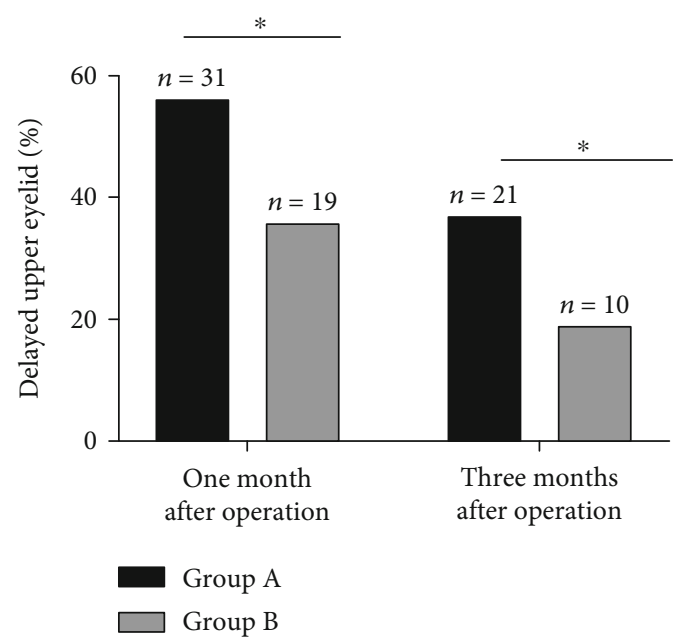

FIgURE 3: Comparison of lid lag after surgery. Lid lag in group B is lower than that in group $A$ at 1 month and 3 months after surgery $(P<0.05) .{ }^{*} P<0.05$ between the two groups. 


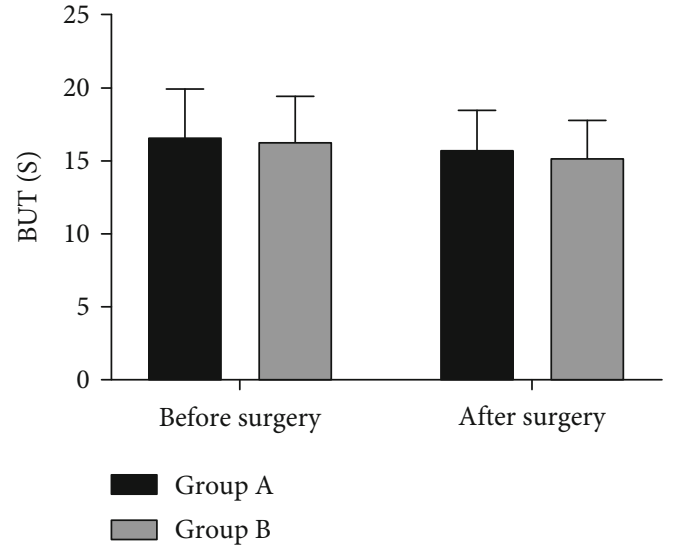

(a)

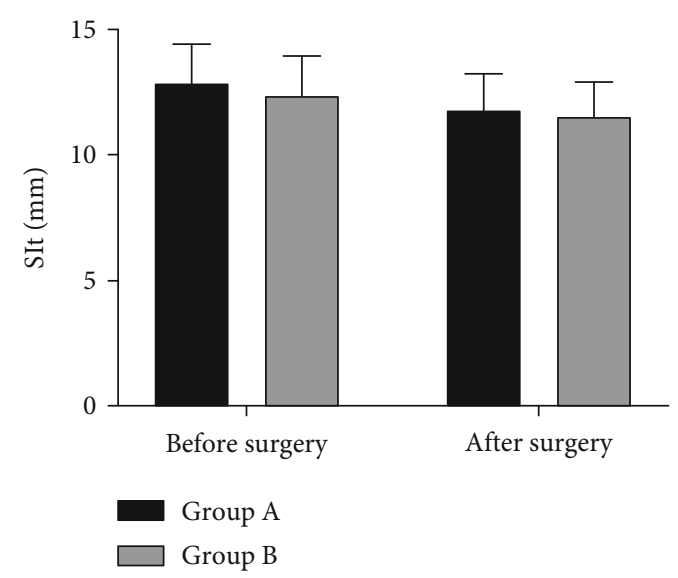

(b)

FIGURE 4: Comparison of ocular surface before and after surgery. (a) Comparison of BUT: there is no significant difference in BUT between the two groups both before and after surgery $(P>0.05)$. (b) Comparison of SIt: there is no significant difference in SIt between the two groups both before and after surgery $(P>0.05)$.

TABLE 2: Comparison of corrective effect $[n(\%)]$.

\begin{tabular}{lcccc}
\hline $\begin{array}{l}\text { Corrective } \\
\text { effect }\end{array}$ & $\begin{array}{c}\text { Group A } \\
(n=57)\end{array}$ & $\begin{array}{c}\text { Group B } \\
(n=53)\end{array}$ & $\chi^{2}$ & $P$ \\
\hline Well corrected & $20(35.09)$ & $36(67.92)$ & - & - \\
Overcorrected & $17(29.82)$ & $8(15.09)$ & - & - \\
Undercorrected & $11(19.30)$ & $6(11.32)$ & - & - \\
Relapse & $9(15.79)$ & $3(5.66)$ & - & - \\
Correction rate & $20(35.09)$ & $36(67.92)$ & 11.851 & $<0.001$ \\
\hline
\end{tabular}

The frontalis muscle and periosteum were separated to the same plane as subcutaneous separation layer, separating the frontalis muscle from the skin at the top and separating the frontalis muscle from the periosteum at the bottom. The inner, middle, and outer points were fixed at the anterior one-third of tarsus. Curvature and height of sutures were adjusted to ensure the normal head-up of patients, and the height of palpebral fissure was controlled to ensure the complete separation of eyelid and eyeball. Afterwards, the incision was sutured to form a double eyelid.

Patients in group B were treated with CFS suspension: all patients were supine anesthetized in the same way as group A. They were operated under the microscope. The marking line was designed, and eyelid infiltration anesthesia was carried out. Skin was cut along the line, and orbicular muscle at the lower edge of the incision was removed to expose tarsus. The incision was separated upward to $5 \mathrm{~mm}$ above the fornix along the space between Muller's muscle and levator aponeurosis, in order to fully expose CFS. Three pairs of mattress sutures were made with 5-0 absorbable suture to fix CFS at the anterior one-third of tarsus so that the upper eyelid margin of the affected eye was located at the upper edge of the cornea when looking straight ahead in a sitting position. Suturing height was adjusted to make the margin of eyelid smooth and natural. 5-0 silk thread was used to lift levator aponeurosis, and the incision was sutured intermittently.

\subsection{Outcome Measures}

2.4.1. Corrective Effect Assessment [11]. Upper eyelid located $1 \sim 2 \mathrm{~mm}$ below the upper corneal margin was considered to be well corrected; upper eyelid located at or above the upper corneal margin was considered to be overcorrected; upper eyelid located $>2 \mathrm{~mm}$ below the upper corneal margin was considered to be undercorrected; no changes in the position of upper eyelid were considered a relapse.

2.4.2. Upper Eyelid Retraction, Lid Lag, and Range of Motion (ROM) at 1 Month and 3 Months after Surgery. ROM determination: the thumb pressed the eyebrow arch to block the traction of the frontalis muscles to upper eyelid. Patients were instructed to look down and then look up to measure the distance of the lowest point of the upper eyelid margin moved.

2.4.3. Ocular Surface. Tear film break-up time (BUT) and Schirmer I test (SIt) were monitored before and one week after surgery. BUT was continuously tested for 3 times, and tear film instability was identified at BUT $<10$ s; SIt was tested for $5 \mathrm{~min}$, and a length of filter paper wetted less than $5 \mathrm{~mm}$ indicated low secretion.

\section{Statistical Analysis}

SPSS 21.0 (SPSS Inc., Chicago, IL, USA) was employed for statistical analysis. The measurement data were expressed by $x \pm \mathrm{SD}$, and the intergroup comparison adopted $t$-test. The counting data were expressed by $[n(\%)]$, and the intergroup comparison adopted chi-square test. Difference was considered statistically significant at $P<0.05$.

\section{Results}

4.1. General Data. There was no difference in general data between the two groups $(P>0.05)$, as shown in Table 1 . 
TABLE 3: Comparison of postsurgical complications $[n(\%)]$.

\begin{tabular}{lccc}
\hline Complication & Group A $(n=57)$ & Group b $(n=53)$ & $\chi^{2}$ \\
\hline Lagophthalmos & $2(3.51)$ & $1(1.89)$ & - \\
Upper eyelid entropion & $1(1.75)$ & $0(0.00)$ & - \\
Exposure conjunctivitis & $3(5.26)$ & $0(0.00)$ & - \\
Hematoma in the eyebrow area & $4(7.02)$ & $2(3.77)$ & - \\
Trichiasis & $4(7.02)$ & $2(3.77)$ & - \\
Conjunctival prolapse & $0(0.00)$ & $0(0.00)$ & - \\
Total incidence rate & $14(24.56)$ & $5(9.43)$ & - \\
\hline
\end{tabular}

4.2. Upper Eyelid Retraction after Surgery. Upper eyelid retraction in group A and group B at 1 month after surgery was $0.65 \pm 0.14 \mathrm{~mm}$ and $0.32 \pm 0.11 \mathrm{~mm}$, respectively, and those values were $0.54 \pm 0.12 \mathrm{~mm}$ and $0.21 \pm 0.07 \mathrm{~mm}$ at 3 months after surgery. It is suggested that the upper eyelid retraction in group B was shorter than that in group A at 1 month and 3 months after surgery $(P<0.05)$, as shown in Figure 1.

4.3. ROM of Upper Eyelid after Surgery. ROM of upper eyelid in group A and group B was $3.68 \pm 0.24 \mathrm{~mm}$ and $5.21 \pm$ $0.35 \mathrm{~mm}$, respectively, at 1 month after surgery, and those values were $5.45 \pm 0.42 \mathrm{~mm}$ and $7.78 \pm 0.48 \mathrm{~mm}$ at 3 months after surgery. The ROM of upper eyelid in group B was larger than that in group $A$ at 1 month and 3 months after surgery $(P<0.05)$, as shown in Figure 2 .

4.4. Lid Lag after Surgery. Lid lag in group A and group B was $56.14 \%$ and $35.85 \%$, respectively, at 1 month after surgery, and those values were $36.84 \%$ and $18.87 \%$ at 3 months after surgery. The lid lag in group B was lower than that in group $\mathrm{A}$ at 1 month and 3 months after surgery $(P<0.05)$, as shown in Figure 3.

4.5. Ocular Surface before and after Surgery. The BUT in group A and group B was $16.68 \pm 3.29 \mathrm{~s}$ and $16.33 \pm 3.18 \mathrm{~s}$, respectively, before surgery, while after surgery, the values were $15.74 \pm 2.78 \mathrm{~s}$ and $15.26 \pm 2.59 \mathrm{~s}$. The SIt in group $\mathrm{A}$ and group B was $12.84 \pm 1.54 \mathrm{~mm}$ and $12.46 \pm 1.48 \mathrm{~mm}$, respectively, before surgery, while after surgery, the values were $11.76 \pm 1.46 \mathrm{~mm}$ and $11.54 \pm 1.32 \mathrm{~mm}$. There was no difference in BUT and SIt between the two groups both before and after surgery $(P<0.05)$, as shown in Figure 4 .

4.6. Comparison of Corrective Effect. Corrective effect in group B was better than that in group A after surgery $(P<0.05)$; see Table 2 .

4.7. Comparison of Complications. Postsurgical complications in group B were fewer than those in group A $(P<0.05)$, as shown in Table 3.

4.8. Comparison of Patient Satisfaction. Patient satisfaction in group $\mathrm{B}$ was higher than that in group $\mathrm{A}(P<0.05)$, as shown in Table 4.
TABLE 4: Comparison of patient satisfaction $[n(\%)]$.

\begin{tabular}{lcccc}
\hline Satisfaction & $\begin{array}{c}\text { Group A } \\
(n=57)\end{array}$ & $\begin{array}{c}\text { Group B } \\
(n=53)\end{array}$ & $\chi^{2}$ & $P$ \\
\hline Highly satisfied & $12(21.05)$ & $24(45.28)$ & - & - \\
$\begin{array}{l}\text { Satisfied } \\
\begin{array}{l}\text { Generally } \\
\text { satisfied }\end{array}\end{array}$ & $21(36.84)$ & $19(35.85)$ & - & - \\
$\begin{array}{l}\text { Dissatisfied } \\
\begin{array}{l}\text { Overall } \\
\text { satisfaction }\end{array}\end{array}$ & $8(28.07)$ & $8(15.09)$ & - & - \\
\hline
\end{tabular}

\section{Discussion}

Ptosis, a common disease encountered in ocular plastic surgery [12], refers to drooping or displacement of the upper eyelid, accompanied by narrowing of vertical palpebral fissure. Ptosis is generally mild and insignificant, but it may cause visual impairment in a few patients whose pupil is completely covered [13-15], affecting the quality of life and increasing the burden. In this study, we compared the efficacy of CFS suspension and frontalis suspension, and it turned out that the upper eyelid retraction, lid lag, and ROM of patients undergoing CFS suspension improved better than those undergoing frontalis suspension. This may be due to the long relaxation time of elastic materials used in frontalis suspension leads to unstable results and upper eyelid retraction. In frontalis suspension, excessive movement of the frontalis muscle may induce inflammation, infection, extravasation, extrusion of materials, eyelid deformation, and involuntary paroxysmal movement of eyelids in the upward direction [16]. In comparison, CFS is less invasive and harmful to tissues and blood vessels and does not change the movement direction of the upper eyelid, thereby reducing lid lag. This may be one of the reasons why CFS suspension is better than frontalis suspension. Tear film is a protective coating lining the outermost layer of corneal epithelium that plays a pivotal role in maintaining eye health $[17,18]$. It prevents excessive evaporation and entry of dust and other foreign particles, resists bacterial infection, lubricates eyelids, and maintains optimal visual performance $[19,20]$. SIt is the most commonly used method to evaluate the production of aqueous tears [21], and BUT has been widely used to measure tear film stability and diagnose common tear issues [22]. Generally, plastic surgery or repair of the upper eyelid may lead to decreased corneal sensation 
and increased tear production in the early stage after surgery. However, in this study, there was no difference in ocular surface alterations between the two groups. Frontalis suspension has no effect on the lacrimal and accessory lacrimal glands and can control tear secretion [23]. Therefore, it is suggested that both CFS suspension and frontalis suspension have no significant influence on the ocular surface of patients.

Our findings demonstrated that CFS resulted in fewer postsurgical complications. In frontalis suspension, materials are used to connect the eyelid to the eyebrow, and dysfunctional eyelid is lifted through the frontalis muscle [24], whereas CFS suspension connects the special muscle sheath of levator in CFS with levator muscle to suspend the eyelid, thus reducing complications such as infection, extrusion, breakage, and granuloma formation. This may also be one of the reasons for higher satisfaction of patients undergoing CFS suspension. There is evidence that CFS suspension has good and lasting efficacy and short recovery time in ptosis, which is worth popularizing [25].

There are several limitations in this study. We have not yet evaluated the effects of the two surgical methods on inflammatory factors nor on the quality of life and revision rates.

To sum up, CFS suspension is effective in the treatment of severe ptosis, with fewer complications and long-lasting efficacy.

\section{Data Availability}

The authors confirm that the data supporting the findings of this study are available within the article.

\section{Conflicts of Interest}

No conflict of interest exists.

\section{Authors' Contributions}

Pengfei Sang, Xun Li, and Mingsong Fang performed the experiments, analyzed the data, and wrote the manuscript. Qingchun Xi and Chang Liu designed the study. All the authors agreed to be accountable for the accuracy and integrity of all aspects of the research.

\section{Acknowledgments}

The work was supported by the Clinical Application Study of Upper Eyelid Combined Fascial Sheath (CFS) in Patients with Severe Ptosis (hwk2018yb004).

\section{References}

[1] S. M. Jacobs, A. J. Tyring, and A. J. Amadi, "Traumatic ptosis: evaluation of etiology, management and prognosis," Journal of ophthalmic \& vision research., vol. 13, pp. 447-452, 2018.

[2] M. A. Elsamkary and M. M. Roshdy, "Clinical trial comparing autogenous fascia lata sling and Gore-Tex suspension in bilateral congenital ptosis," Clinical Ophthalmology, vol. 10, pp. 405-409, 2016.
[3] Y. Wang, Y. Xu, X. Liu, L. Lou, and J. Ye, “Amblyopia, strabismus and refractive errors in congenital ptosis: a systematic review and meta-analysis," Scientific Reports, vol. 8, p. 8320, 2018.

[4] M. Marenco, I. Macchi, I. Macchi, E. Galassi, M. MassaroGiordano, and A. Lambiase, "Clinical presentation and management of congenital ptosis," Clinical Ophthalmology, vol. 11, pp. 453-463, 2017.

[5] A. J. Park, B. Eliassi-Rad, and M. A. Desai, "Ptosis after glaucoma surgery," Clinical Ophthalmology, vol. 11, pp. 14831489, 2017.

[6] Y. Takahashi, I. Leibovitch, and H. Kakizaki, "Frontalis suspension surgery in upper eyelid blepharoptosis," The open ophthalmology journal, vol. 4, pp. 91-97, 2010.

[7] A. Naik, A. Patel, N. Bothra, L. Panda, M. N. Naik, and S. Rath, "Endoscope-assisted harvest of autogenous fascia lata in frontalis suspension surgery: a minimally invasive approach revisited," Indian Journal of Ophthalmology, vol. 66, pp. 440-444, 2018.

[8] K. P. Shah and B. Mukherjee, "Efficacy of frontalis suspension with silicone rods in ptosis patients with poor Bell's phenomenon," Taiwan journal of ophthalmology, vol. 7, pp. 143-148, 2017.

[9] B. Li, J. Yang, W. Wu et al., “Anatomical and histological study of the conjoint fascial sheath of the levator and superior rectus for ptosis surgery," Ophthalmic Plastic and Reconstructive Surgery, vol. 36, no. 6, pp. 617-620, 2020.

[10] J. Finsterer, "Ptosis: causes, presentation, and management," Aesthetic Plastic Surgery, vol. 27, pp. 193-204, 2003.

[11] L. Zuo, X. X. Wang, X. Y. Huang, J. L. Zhang, and Y. Y. Du, “A modified levator resection technique involving retention of the levator palpebrae superioris muscle suspension system for treatment of congenital ptosis," Aesthetic Plastic Surgery, vol. 41, pp. 856-862, 2017.

[12] J. W. Yang, "Modified levator muscle resection using Putterman Muller's muscle-conjunctival resection-ptosis clamp," Aesthetic Surgery Journal, vol. 38, pp. 480-487, 2018.

[13] P. Pavone, S. Y. Cho, A. D. Pratico, R. Falsaperla, M. Ruggieri, and D. K. Jin, "Ptosis in childhood: a clinical sign of several disorders: case series reports and literature review," Medicine, vol. 97, article e12124, 2018.

[14] J. S. Paik, S. A. Kim, S. H. Park, and S. W. Yang, "Refractive error characteristics in patients with congenital blepharoptosis before and after ptosis repair surgery," BMC Ophthalmology, vol. 16, p. 177, 2016.

[15] R. A. Harrad, C. M. Graham, and J. R. Collin, "Amblyopia and strabismus in congenital ptosis," Eye, vol. 2, Part 6, pp. 625$627,1988$.

[16] W. Chen, Z. Liu, Q. Tian et al., "Levator resection with suspensory ligament of the superior fornix suspension for correction of pediatric congenital ptosis with poor levator function," Eye, vol. 30, pp. 1490-1495, 2016.

[17] M. Patterson, H. J. Vogel, and E. J. Prenner, "The effect of repeated lateral compression and expansions mimicking blinking on selected tear film polar lipid monofilms," Biochimica et Biophysica Acta - Biomembranes, vol. 1859, pp. 319-330, 2017.

[18] M. S. Milner, K. A. Beckman, J. I. Luchs et al., "Dysfunctional tear syndrome: dry eye disease and associated tear film disorders - new strategies for diagnosis and treatment," Current Opinion in Ophthalmology, vol. 27, Supplement 1, pp. 3-47, 2017. 
[19] A. Guarnieri, E. Carnero, A. M. Bleau et al., "Ocular surface analysis and automatic non-invasive assessment of tear film breakup location, extension and progression in patients with glaucoma," BMC Ophthalmology, vol. 20, p. 12, 2020.

[20] G. A. Georgiev, P. Eftimov, and N. Yokoi, "Structure-function relationship of tear film lipid layer: a contemporary perspective," Experimental Eye Research, vol. 163, pp. 17-28, 2017.

[21] K. W. Jin, J. W. Ro, Y. J. Shin, J. Y. Hyon, W. R. Wee, and S. G. Park, "Correlation of vitamin D levels with tear film stability and secretion in patients with dry eye syndrome," Acta Ophthalmologica, vol. 95, pp. e230-e235, 2017.

[22] H. Pena-Verdeal, C. Garcia-Resua, L. Ramos, E. Yebra-Pimentel, and M. J. Giraldez, "Diurnal variations in tear film breakup time determined in healthy subjects by software-assisted interpretation of tear film video recordings," Clinical \& Experimental Optometry, vol. 99, pp. 142-148, 2016.

[23] K. Li, X. C. Zhang, X. X. Cai, Y. D. Quan, and R. Lu, "The inflammation influence on corneal surface after frontalis suspension surgery," International Journal of Ophthalmology, vol. 11, pp. 1489-1495, 2018.

[24] F. Ali, M. S. Khan, M. Sharjeel, Z. U. Din, B. Murtaza, and A. Khan, "Efficacy of brow suspension with autogenous fascia lata in simple congenital ptosis," Pakistan journal of medical sciences, vol. 33, pp. 439-442, 2017.

[25] J. Zhou, W. Chen, Z. Qi, and X. Jin, "Minimally invasive conjoint fascial sheath suspension for blepharoptosis correction," Aesthetic Plastic Surgery, vol. 43, pp. 956-963, 2019. 